\title{
Laser Cleaning Using Q-Switched Nd:YAG Laser of Low Carbon Steel Alloys
}

\author{
S. N. Ali, Z. A. Taha, and T. S. Mansour \\ Institute of Laser for Postgraduate Studies, University of Baghdad, Baghdad, Iraq \\ Correspondence should be addressed to Z. A. Taha; zddiesel@yahoo.com
}

Received 27 February 2014; Revised 27 April 2014; Accepted 28 April 2014; Published 20 May 2014

Academic Editor: Kai Sun

Copyright (C) 2014 S. N. Ali et al. This is an open access article distributed under the Creative Commons Attribution License, which permits unrestricted use, distribution, and reproduction in any medium, provided the original work is properly cited.

\begin{abstract}
This paper represents the efforts to achieve the laser cleaning process of low carbon steel alloys AISI1005 and AISI1012 with $0.65 \mathrm{~mm}$ and $1 \mathrm{~mm}$ thickness, respectively. The cleaning experiments were performed with a Q-switched Nd:YAG nanosecond laser at wavelengths of $1064 \mathrm{~nm}$ and $532 \mathrm{~nm}$. The parameters that have been selected for the present work are peak power which varies as $5,15,30,40$, and $50 \mathrm{MW}$ and pulse repetition rate which varies from 1 to $6 \mathrm{~Hz}$ by $1 \mathrm{~Hz}$ increment. Effects of these parameters on the microstructure and the mechanical properties of the two alloys have been realized. Also predicted results of analytical model regarding the depth were compared with the experimental results which show a good agreement between both.
\end{abstract}

\section{Introduction}

Laser cleaning is considered to be the process which is in possession of big effects in cleaning processes in the near future and it has become a real alternative to mechanical and chemical techniques to remove contaminants from a large set of materials which are environmentally costly [1].

Laser cleaning has been considered as a promising technique to directly ablate contaminants without altering or affecting bulk properties in numerous applications [2]. Compared to conventional mechanical or chemical methods, laser techniques have the benefit of a versatile and selective process of removing specific substances using appropriate laser parameters, such as wavelength, frequency, and intensity [3].

The one-dimensional temperature rise in the sheet is described by the following [4]:

$$
\begin{aligned}
& \Delta T(z, t) \\
& =\frac{1}{K_{m}} \sqrt{\frac{D_{m}}{\pi}}\left\{\int_{0}^{t} I a(t-\tau) \frac{e^{-z^{2}}\left(4 D_{m} \tau\right)}{\sqrt{\tau}} d \tau\right. \\
& +\sum_{n-1}^{\infty} \int_{0}^{t} \frac{I a(t-\tau)}{\sqrt{\tau}}\left[e^{-(2 n l-z)^{2} /\left(4 D_{m} \tau\right)}\right. \\
& \left.\left.+e^{-(2 n l+z)^{2} /\left(4 D_{m} \tau\right)}\right] d \tau\right\},
\end{aligned}
$$

where

$$
\begin{gathered}
\Delta T(z, t)=\frac{2 F}{\sqrt{\pi K_{m} \rho_{m} C_{m} t}} \\
I a(t)=(1-R) I l(t),
\end{gathered}
$$

where $z$ represents the removed depth $(\mu \mathrm{m}) ; t$ is the interaction time (sec); $\tau$ is the integration variable (sec); $n$ is an integer number for simulation; $K_{m}$ is the thermal conductivity of the metal $\left(\mathrm{W} / \mathrm{m} \cdot{ }^{\circ} \mathrm{k}\right) ;\left(D_{m}=K_{m} / \rho_{m} \cdot C_{m}\right)[4]$ is the diffusivity of the metal $\left(\mathrm{m}^{2} / \mathrm{s}\right) ; \rho_{m}$ is the density of the metal $\left(\mathrm{Kg} / \mathrm{m}^{3}\right) ; C_{m}$ is the specific heat of the metal $\left(\mathrm{J} / \mathrm{Kg} \cdot{ }^{\circ} \mathrm{k}\right) ; I_{a}(t)$ is the absorption intensity $\left(\mathrm{W} / \mathrm{m}^{2}\right) ; F$ represents the fluence $\left(\mathrm{J} / \mathrm{m}^{2}\right) ; I l(t)$ is the incident laser intensity; and $R$ is the reflectivity of the contaminant layer; since rust and lubricant are oblique materials, then their transitivity equals zero; as a result $(1-R)=A[4]$.

Equation (1) represents the method to simulate the removed depth analytically. Lasers can remove unwanted layers that conventional techniques cannot remove safely [5]. Ahn et al. showed that a near-infrared (NIR) laser pulse provides an effective tool for removing lubricants from carbon steel surfaces [6]. Such a unique case of technological and methodological processes was entirely determined by the scientific contribution provided by various research institutions [7]. 


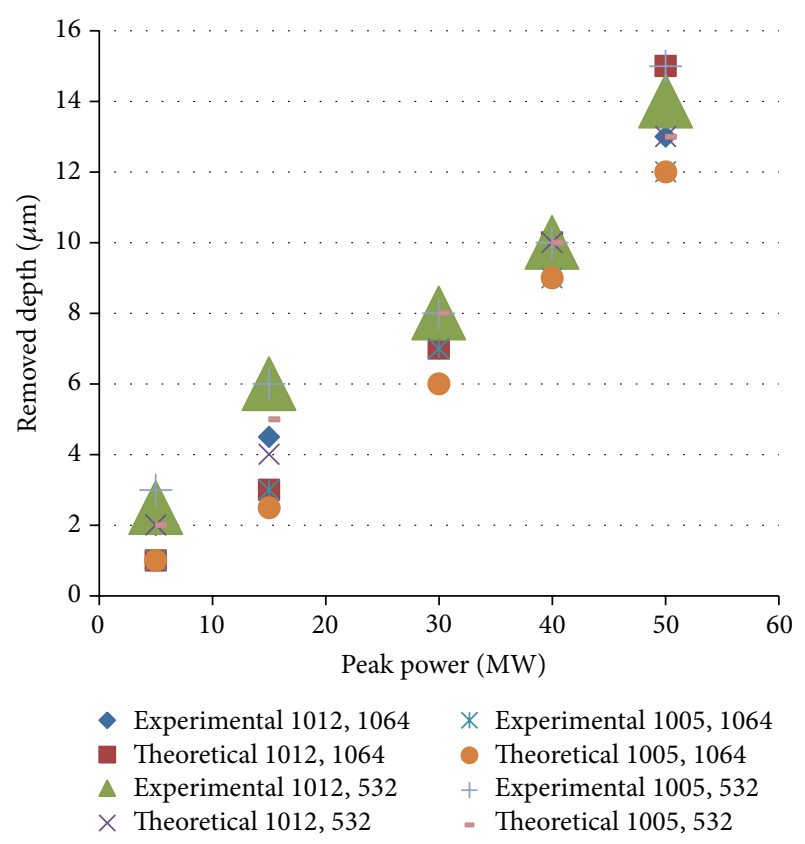

FIGURE 1: Removed depth at different peak powers, wavelengths of 1064 and 532, and PRR of $4 \mathrm{~Hz}$ for AISI1012 and AISI1005.

\section{Experimental Details}

The laser beam is delivered using an optical fiber. The laser spot for this work was fixed on the sample surface at $2 \mathrm{~mm}$ in diameter which is focused perpendicularly on the surface of $20 \times 20 \mathrm{~mm}^{2}$ in area. The steel plates were covered with a thin film of contaminant layer (rust and lubricant).

Processed samples were examined with optical microscope $(\mathrm{OM})$ of $(200 \mathrm{x})$ which is beside its main job to examine the microstructure of the samples, the (OM) is measured experimentally the removed depth of ablation by using the circular ruler in the side of this device which its scale in micrometer. Roughness tester was used to distinguish between the average roughness $(\mathrm{Ra})$ before and after laser cleaning process; microhardness tester was used to examine the effects on the mechanical properties of the base metal surface; UV-VIS-NIR spectrophotometer was used to show the absorptivity of the contaminant layer [ $A$ is the absorptivity of the contamination which has value of $(A=0.89)$ that was measured experimentally] on both metals to both wavelengths of the laser system of this work, and SEM was used to experiment the microstructure of the samples after being irradiated by laser beam to check for the existence of laser cleaning effect.

\section{Simulation Results}

The present computer model agreed well with experimental in most situations, where the depth of ablation in both experimental and computational results was approximately similar in most cases as shown in Figures 1 and 2. As shown in these figures, the removed depth increased with the increase of both pulse repetition rate and peak power. The process of

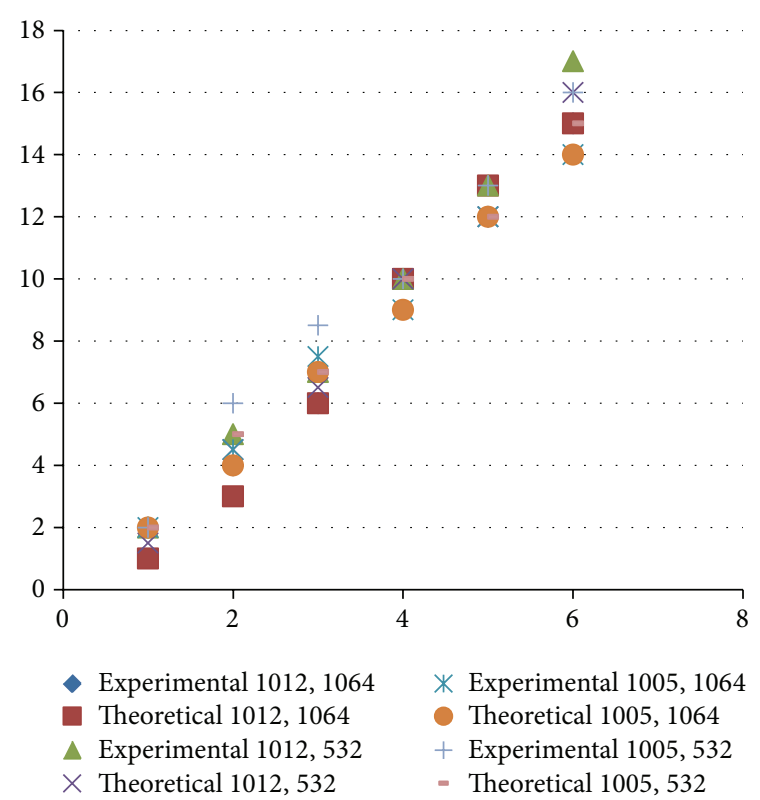

FIGURE 2: Removed depth at different PRR, wavelengths of 1064 and 532, and peak power of $40 \mathrm{MW}$ for AISI1012 and AISI1005.

removing reached a reasonable value at PRR of $4 \mathrm{~Hz}$ and $P_{p}$ of $40 \mathrm{MW}$.

\section{Experimental Results}

4.1. Peak Power Effect. Laser ablation threshold is defined as the minimum fluence value at which there is a detectable removal of matter (contaminant layer) from the surface of a metal subjected to laser irradiation [8]. In this sense, peak power effect, which is closely connected to laser cleaning efficiency, plays a key role on surface processing quality.

Figure 3 displays scanning electron microscope (SEM) image of processing results at the optimum values of peak power and pulse repetition rate of $40 \mathrm{MW}$ and $4 \mathrm{~Hz}$, respectively, while Figure 4 represents the optical microscope (OM) image of processing results at optimum value of peak power and pulse repetition rate of $40 \mathrm{MW}$ and $4 \mathrm{~Hz}$, respectively.

The surface roughness of processed low carbon steel (L.C.S.) substrates is illustrated in Figure 5. The roughness at a low laser peak power is high due to the existence of uneven processing residues. Once the laser peak power reaches $15 \mathrm{MW}$, surface roughness starts to decrease. This reveals that a high laser peak power provides effective elimination of residues for a thin layer of contaminant (in $\mu \mathrm{m}$ ). Control experiments show that Nd:YAG laser ablation offers full cleaning with reasonable surface roughness due to substrate free damage.

The microhardness of the base metals is $350 \mathrm{HV}$ for AISI 1005 and $108 \mathrm{HV}$ for AISI 1012. As shown in Figure 6, the microhardness of cleaned samples is rather increased as the laser peak power increases. This indicates that the contaminant layer is removed efficiently from L.C.S. plates through a thermal decomposition process. 


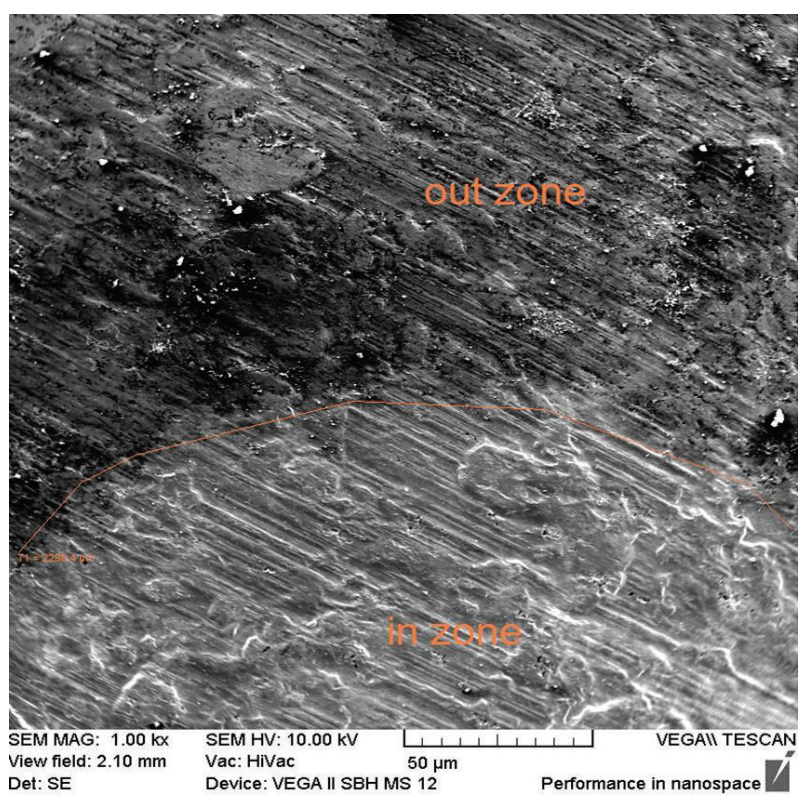

Figure 3: SEM image 1000x at $P_{p} 40 \mathrm{MW}$ and PRR $4 \mathrm{~Hz}$.

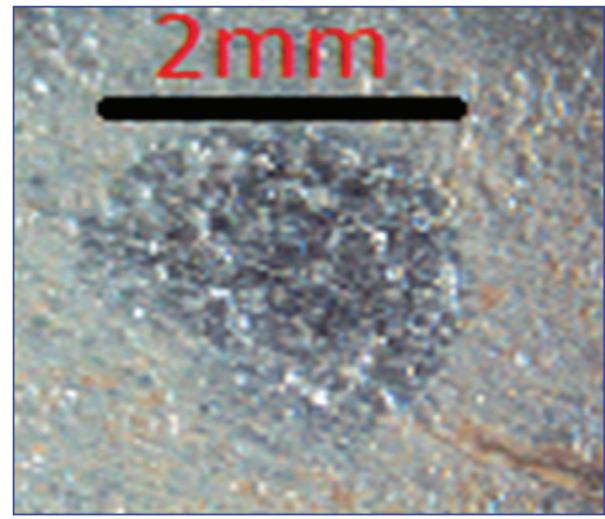

Figure 4: OM image 200x at PRR $=4 \mathrm{~Hz} ; P_{p}=40 \mathrm{M}$.

Figure 7 represents the relationship between the depth and $P_{p}$ at PRR of $4 \mathrm{~Hz}$ for AISI 1012 and AISI 1005 at 1064 and $532 \mathrm{~nm}$.

4.2. Pulse Repetition Rate (PRR) Effect. Q-switched nanosecond pulsed laser has a benefit in the cleaning process, since no heat load into the bulk of the material has been affected during the pulse [9].

When the PRR has been increased, removal depth has also increased as shown in Figure 8.

In this research, the values of (P.R.R.) were measured at 1 second in all experiments. To facilitate the theoretical analyses and to Unification the experiments process.

An important observation can be seen in Figure 9; that is, in the experiments of this study, when the pulse repetition rate is $4 \mathrm{~Hz}$ the optimum value was found, at which the microhardness did not exceed the reasonable value; at the same time other base metal mechanical properties such as roughness (Figure 10) explained that surface roughness was

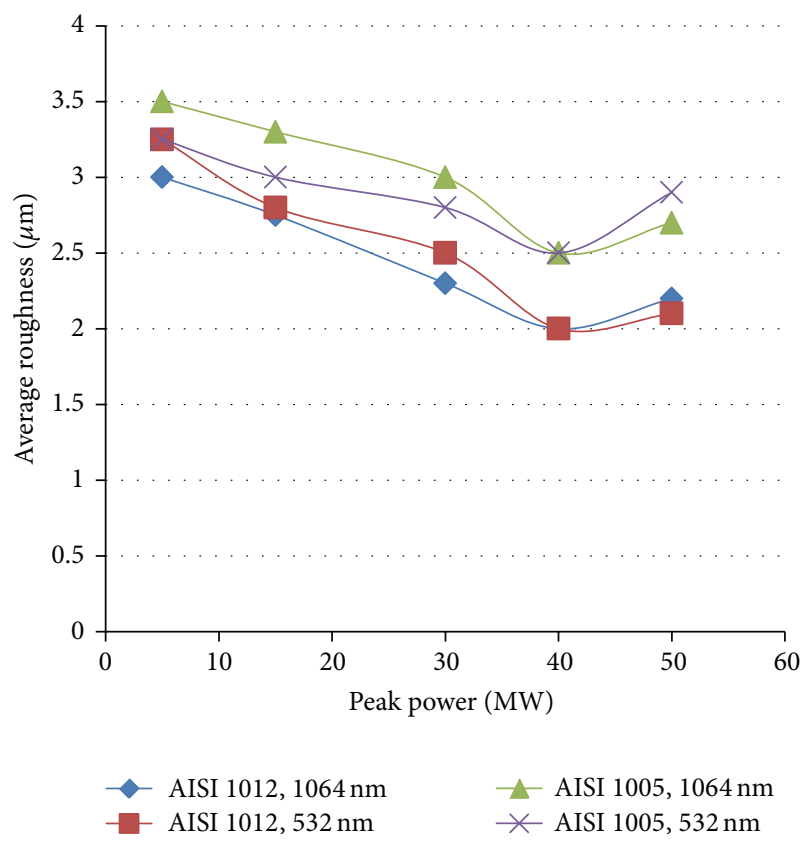

Figure 5: Variation of $R_{a}$ as a function of $P_{p}$ at PRR $4 \mathrm{~Hz}$.

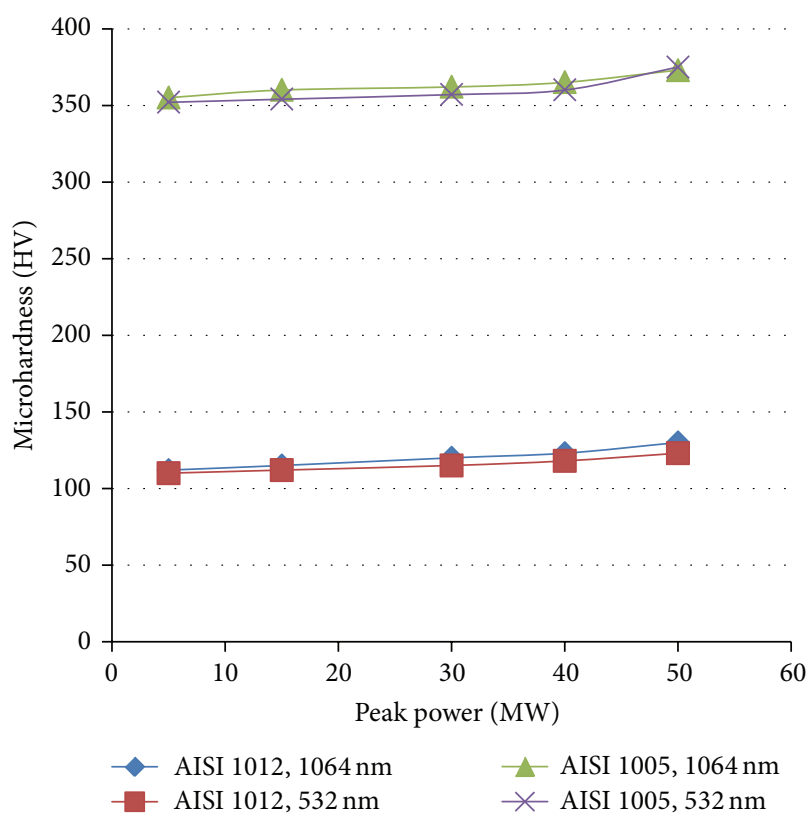

FIgURE 6: Variation of microhardness as a function of $P_{p}$ at PRR $4 \mathrm{~Hz}$.

decreased during the cleaning process. It was also found that by changing the number of laser pulses and the value of energy density the roughness of the cleaned surface can be changed [10].

The scanning electron microscope (SEM) (Figure 3) and the optical microscope $(\mathrm{OM})$ (Figure 4) show the effects at the optimum values of $P_{p}(40 \mathrm{MW})$ and PRR $(4 \mathrm{~Hz})$. From Figures 3 and 4 , also the experiment at $P_{p}$ of $40 \mathrm{MW}$ and PRR of $4 \mathrm{~Hz}$ shows an acceptable cleaning effect that is related to 


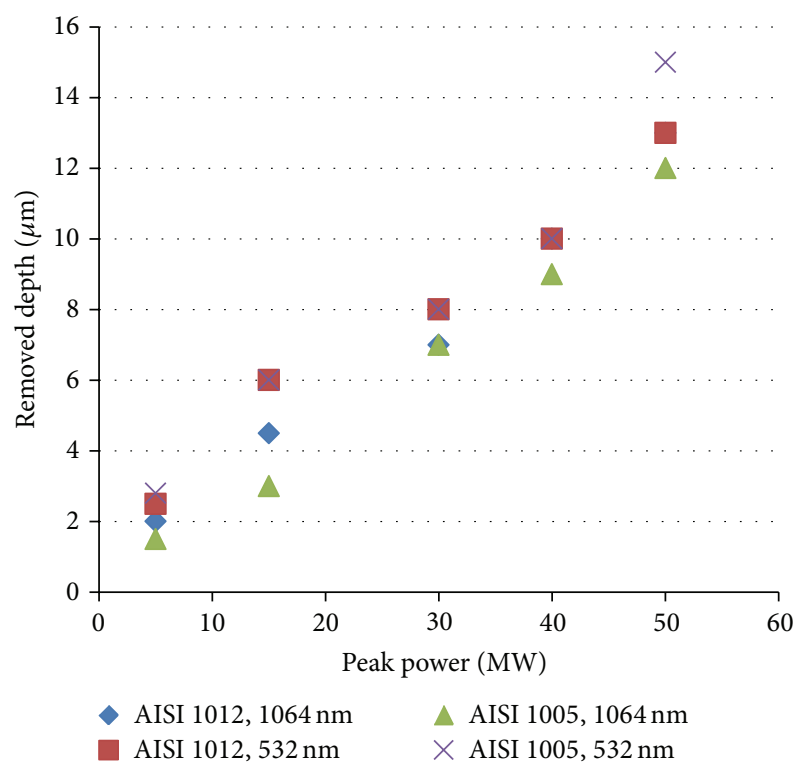

FIgURE 7: Variation of depth as a function of $P_{p}$ at PRR $4 \mathrm{~Hz}$.

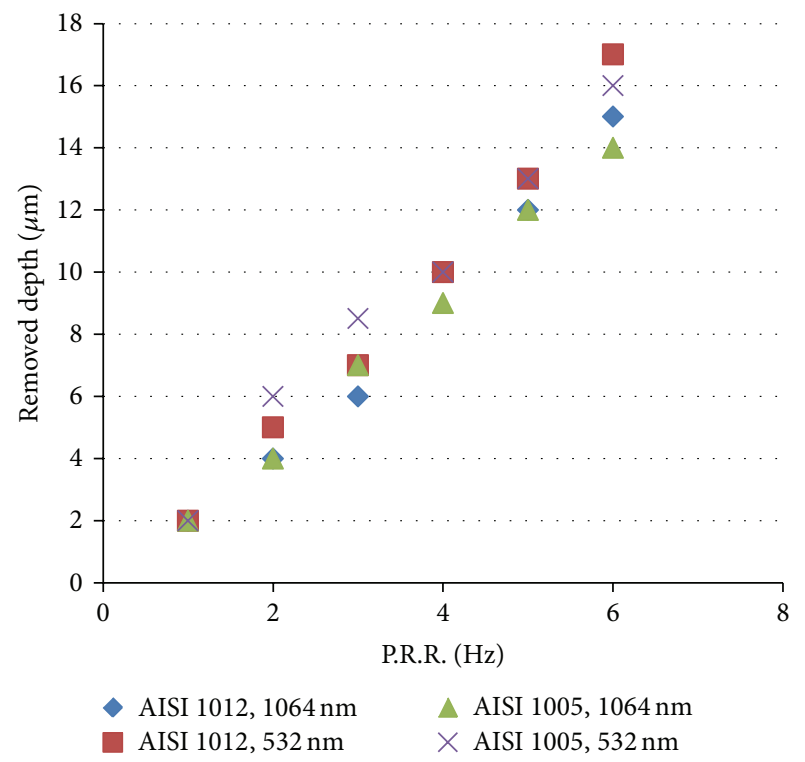

FIgURE 8: Variation of depth as a function of PRR at $P_{p} 40 \mathrm{MW}$.

good matching between cleaning process and unaffected base metal properties.

4.3. Wavelength Effect. In this research, experiments showed in the process supported by analytical calculations that there is no substantial difference or significant impact on mineral specimens when using the laser wavelength $1064 \mathrm{~nm}$ or 532 .

The influence of wavelength on the cleaning efficiency can be ascribed to two aspects. First, the substrate absorption coefficient of laser light is different for different wavelengths. Second, the interaction of laser light with contaminant layer results in localized light intensity near the contaminant layersubstrate contacting area, which is highly related to the

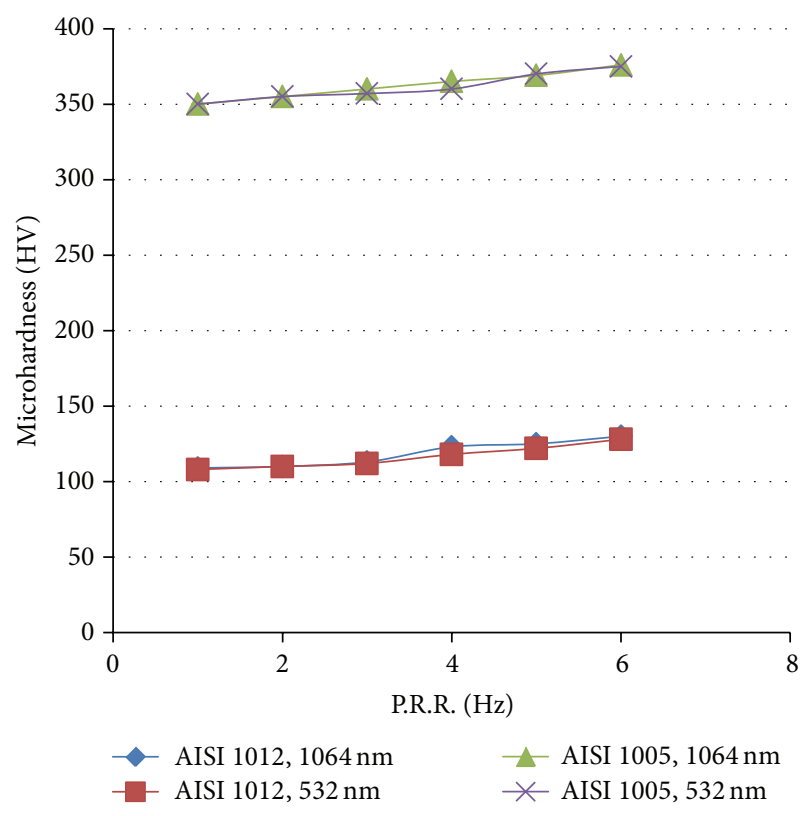

FIGURE 9: Variation of microhardness as a function of PRR at $P_{p}$ $40 \mathrm{MW}$.

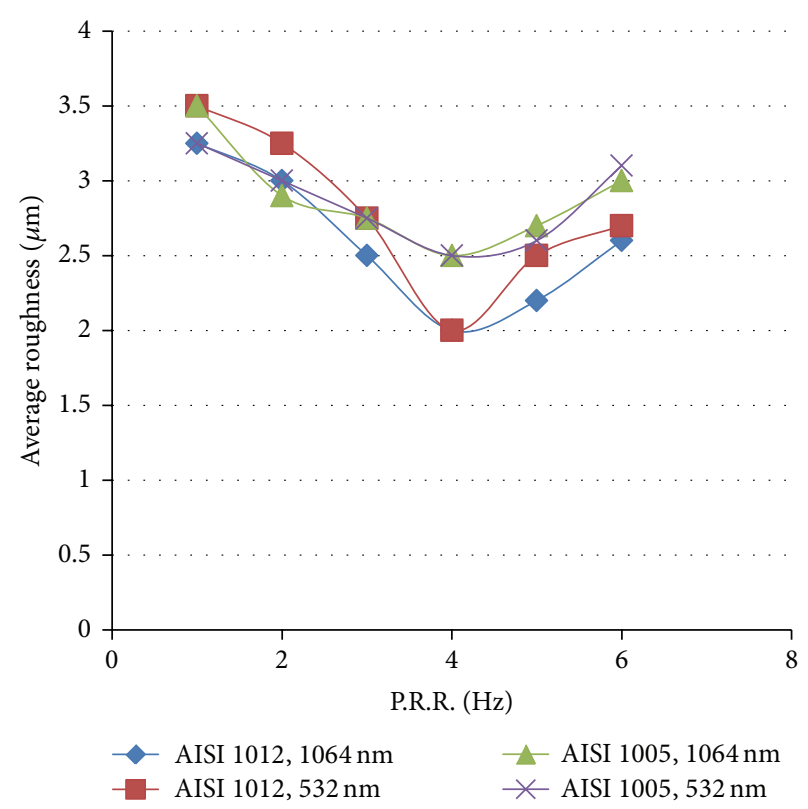

FIgURE 10: Variation of $\left(R_{a}\right)$ as a function of PRR at $P_{p} 40 \mathrm{MW}$.

wavelength and contaminant layer thickness. Nd:YAG laser with fundamental wavelength of $1064 \mathrm{~nm}$ and its second harmonic wavelength of $532 \mathrm{~nm}$ has a significant effect of cleaning process for the metal samples from lubricant and rust, this is returned to the high absorptivity of lubricant and rust for these wavelengths [11]. Infrared radiation at $1064 \mathrm{~nm}$ with ns pulse duration emitted from a Q-switched Nd:YAG laser was found to be able to remove rust layer products from low carbon steel plates with quite satisfactory results [12]. 


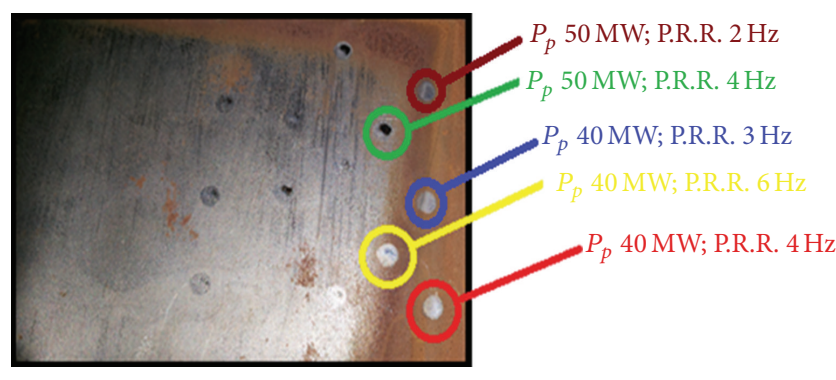

FIgURE 11: Photographic image of workpiece.

\section{Discussion}

In Figures 1 and 2, comparison between the theoretical and experimental removed depth of AISI1012 and AISI1005 samples at different peak power $\left(P_{p}\right)$ and pulse repetition rate (PRR), respectively, was shown for both wavelengths $1064 \mathrm{~nm}$ and $532 \mathrm{~nm}$. There are no big differences in the results between them. This is due to the fact that the absorption coefficient of the contaminant layer is the same for both wavelengths; as a result, the cleaning process effect has the same behavior for both wavelengths.

The mechanical and optical investigations show that $P_{p}$ of $40 \mathrm{MW}$ and PRR of $4 \mathrm{~Hz}$ are the optimum values for cleaning process since the mechanical and microstructure properties of the base metal surfaces were unaffected, as it is clear from microhardness, roughness, optical microscope and scanning electron microscope tests.

Increasing the laser peak power and the PRR shows more removal depth and consequently the other side effects were increased too, since it will affect the base metal surface as shown in Figure 11, where the green and yellow color zones show black due to the high power. Partial blackness results of high PRR were also shown in Figure 11. Optimum conditions have been taken according to best cleaning effects without affecting the base metal surface.

The efficiency of the cleaning process using a Q-switched Nd:YAG laser came from the high absorbance $(A=0.89)$ of the layer of contaminants (rust and grease) for both wavelengths of the Nd:YAG laser.

The average surface roughness of contaminant layer is $\left(R_{\mathrm{ave}}=3.5\right)$, while the average surface roughness of the metals is $\left(R_{\text {ave }}=2\right)$. The difference between $\left(R_{\text {avg. }}\right)$ of the contaminant layer and metal surface makes the absorptivity of contaminant layer higher than that of base metal surface; therefore laser cleaning process will be clear on a layer of pollutants. They absorb this beam at pulse duration of $10 \mathrm{~ns}$ of the laser beam; due to this duration the impact of radiation did not affect the base metal surface.

In addition to that the melting point of these pollutants is much less than the melting point of metals, as a result the contaminants layer have completely removed without damaging the surface of the metal base, this is accord according to the optimum values for each of the peak power and pulse repetition rate.

\section{Conclusions}

The results show that it is possible to control the depth of the laser cleaning area by precisely controlling the laser output parameters. As the number of pulses increases; the depth of removal layer increases too [13].

In all cases of the present study, a removal layer of the contaminants from the surface of the samples varies depending on the real interaction time. Particularly in this work the microstructures of the base metals remain unchanged in overall cases as shown in SEM test.

Microhardness tests show that for AISI 1005 microhardness increasing with percentage is about $4 \%$ and for AISI 1012 microhardness increasing with percentage is about $13 \%$; an increment in microhardness for optimum laser cleaning condition $\left(P_{p} 40 \mathrm{MW}, \mathrm{PRR} 4 \mathrm{~Hz}\right)$ is acceptable in comparison to the total scale of $\mathrm{HV}$ which is $1000 \mathrm{HV}$ for carbon steel alloys. So, it can be said that there were almost no effects in microhardness values during laser cleaning process. The optimization of all parameters is essential in defining the best laser cleaning conditions for each case [14]. With nanosecond laser pulses, better cleaning quality was achieved when high laser fluence (below substrate damage threshold) were applied $[15,16]$.

The computational results show the same behavior of the experimental work.

\section{Conflict of Interests}

The authors declare that there is no conflict of interests regarding the publication of this paper.

\section{Acknowledgments}

This work was supported by the Institute of Laser for Postgraduate Studies, University of Baghdad, and the Ministry of Higher Education and Scientific Research, Baghdad, Iraq.

\section{References}

[1] J. Perrière, E. M. illon, and E. F. ogarassy, Recent Advances in Laser Processing of Materials, Handbook, 1st edition, 2006.

[2] Y. C. Guan, G. K. L. Nga, H. Y. Zheng et al., "Laser surface cleaning of carbonaceous deposits on diesel engine piston," Applied Surface Science, vol. 270, pp. 526-530, 2013.

[3] G. X. Chen, T. J. Kwee, K. P. Tan, Y. S. Choo, and M. H. Hong, "Laser cleaning of steel for paint removal," Applied Physics A: Materials Science and Processing, vol. 101, no. 2, pp. 249-253, 2010.

[4] S. Siano and R. Salimbeni, "Advances in laser cleaning of artwork and objects of historical interest: the optimized pulse duration approach," Accounts of Chemical Research, vol. 43, no. 6, pp. 739-750, 2010.

[5] E. Drakaki, M. Kandyla, E. Chatzitheodoridis et al., "Laser studies of metallic artworks," Applied Physics A: Materials Science and Processing, vol. 101, no. 2, pp. 349-355, 2010.

[6] D. Ahn, D. Jang, T. Park, and D. Kim, "Laser removal of lubricating oils from metal surfaces," Surface and Coatings Technology, vol. 206, no. 18, pp. 3751-3757, 2012.

[7] S. Siano, J. Agresti, I. Cacciari et al., "Laser cleaning in conservation of stone, metal, and painted artifacts: state of the art and 
new insights on the use of the Nd:YAG lasers," Applied Physics A: Materials Science and Processing, vol. 106, no. 2, pp. 419-446, 2012.

[8] M. P. Mateo, T. Ctvrtnickova, E. Fernandez, J. A. Ramos, A. Yáñez, and G. Nicolas, "Laser cleaning of varnishes and contaminants on brass," Applied Surface Science, vol. 255, no. 10, pp. 5579-5583, 2009.

[9] G. Buccolieri, V. Nassisi, A. Buccolieri et al., "Laser cleaning of a bronze bell," Applied Surface Science, vol. 272, pp. 55-58, 2013.

[10] A. V. Rode, K. G. H. Baldwin, A. Wain et al., "Ultrafast laser ablation for restoration of heritage objects," Applied Surface Science, vol. 254, no. 10, pp. 3137-3146, 2008.

[11] H. Garbacz, E. Fortuna, J. Marczak et al., "Laser cleaning of copper roofing sheets subjected to long-lasting environmental corrosion," Applied Physics A: Materials Science and Processing, vol. 100, no. 3, pp. 693-701, 2010.

[12] I. Cacciari, D. Ciofini, M. Mascalchi, A. Mencaglia, and S. Siano, "Novel approach to the microscopic inspection during laser cleaning treatments of artworks," Analytical and Bioanalytical Chemistry, vol. 402, no. 4, pp. 1585-1591, 2012.

[13] A. Siatou, D. Charalambous, V. Argyropoulos et al., "A comprehensive study for the laser cleaning of corrosion layers due to environmental pollution for metal objects of cultural value: preliminary studies on artificially corroded coupons," Laser Chemistry, vol. 2006, Article ID 85324, 7 pages, 2006.

[14] M. W. Steen and J. Mazumder, Laser Material Processing, Springer, 4th edition, 2010.

[15] N. Carmona, M. Oujja, H. Roemich, and M. Castillejo, "Laser cleaning of 19th century Congo rattan mats," Applied Surface Science, vol. 257, no. 23, pp. 9935-9940, 2011.

[16] S. Pentzien, A. Conradi, R. Koter, and J. Krüger, "Cleaning of artificially soiled paper using nanosecond, picosecond and femtosecond laser pulses," Applied Physics A: Materials Science and Processing, vol. 101, no. 2, pp. 441-446, 2010. 

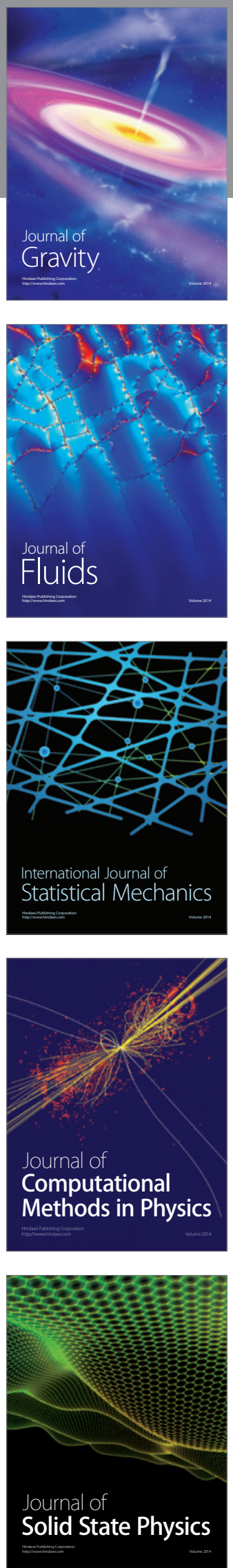

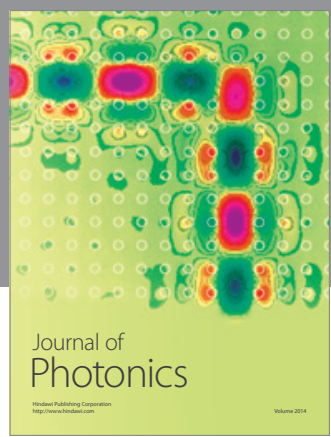

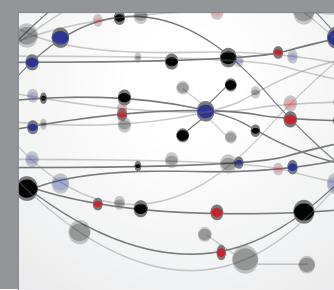

The Scientific World Journal

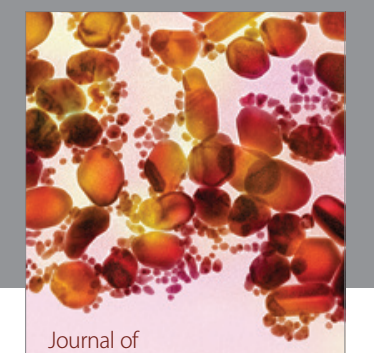

Soft Matter
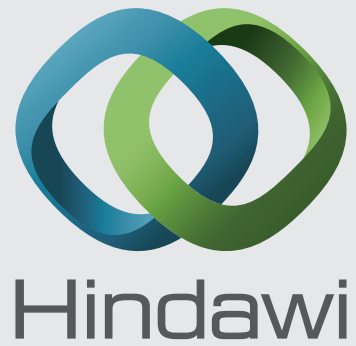

Submit your manuscripts at

http://www.hindawi.com
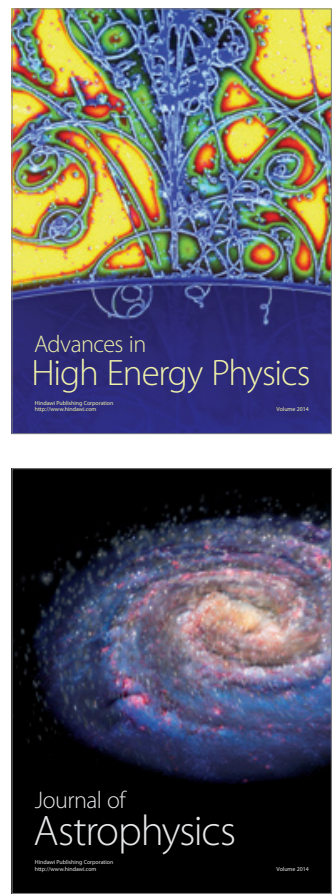
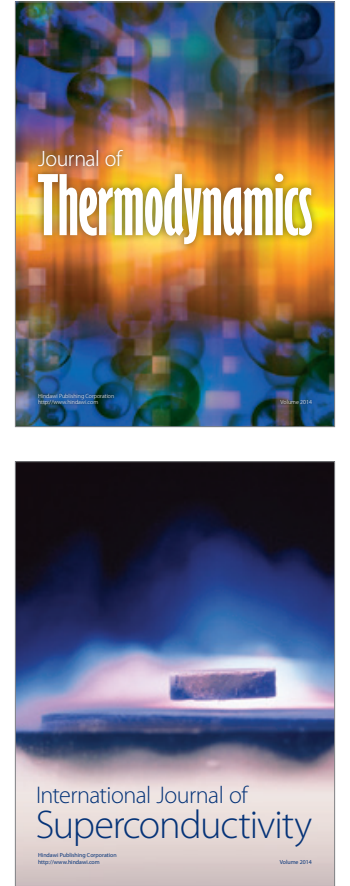
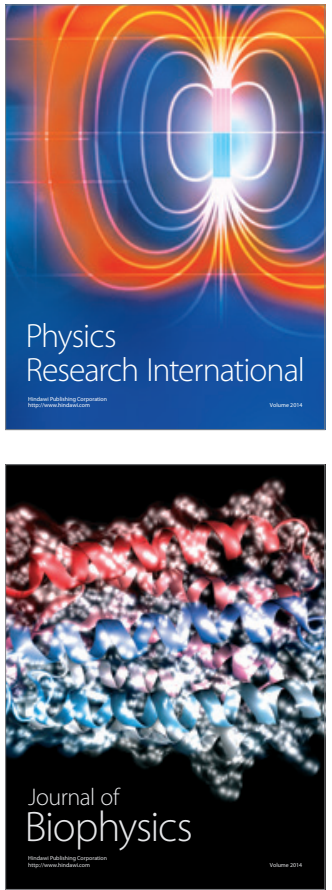
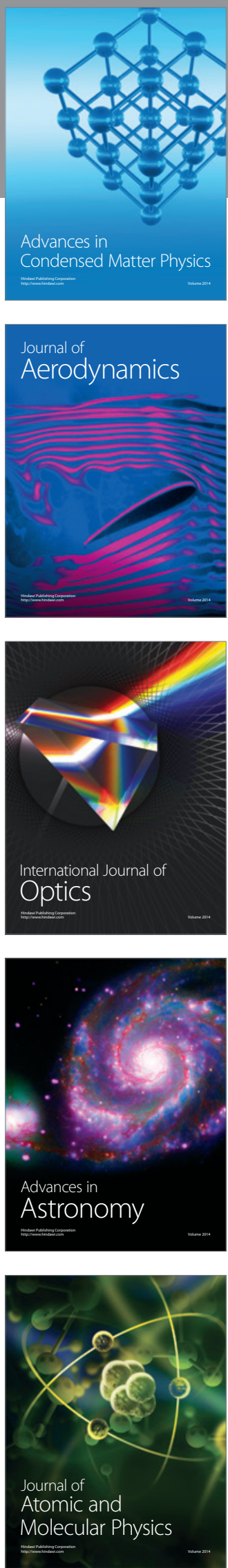